\title{
A COMPREHENSIVE ANALYTICAL CONCEPTUAL FRAMEWORK FOR MANGO SUPPLY CHAIN EXPORT
}

\author{
Assoc. Prof. Dr. Le Nguyen Doan Khoi, \\ Scientific Affairs Department, Can Tho University \\ $\underline{\text { http://doi.org/10.35409/IJBMER.2019.2417 }}$
}

\begin{abstract}
This article presents the conceptual framework used for an export-oriented mango supply chain. It provides a structure to the description and analysis of the supply chain based on which the performance of a supply chain can be assessed in order to find possible improvements. Consequently, the conceptual model gives a clear picture of the structure of the study and shows how the theory is linked to practice.
\end{abstract}

Keyword: Mango supply chain, export-oriented, Mekong Delta

\section{INTRODUCTION}

Exporting products from developing countries means that one has to deal with deficiencies in infrastructural resources. In many cases the transportation networks, telecommunication facilities, worker skills, material quality and (technical) equipment are on a lower level than in the developed world. The advice that will be given in this study will help to design the supply chain in such a way that these differences between developing countries and developed countries can be best overcome.

In order to maximize the profitability of the mango-export in Vietnam in general and in the Mekong Delta (MD) in particular, the supply chain has to be optimized. This objective may suggest that the whole supply chain will be taken into consideration. In fact, the analysis starts at the production of mangoes and stops at the moment that mangoes have arrived at the (air)port of destination in Europe. The commercialization in Europe does not fall within the scope of the research. Furthermore a distinction has to be made between the supply chains of fresh mangoes and processed or dried mangoes. Fresh mangoes are perishable and therefore require different logistics than the processed and dried ones. The focus of this research lies on the logistical part of the supply chain of fresh mangoes, where seemingly small problems can cause huge losses. In practice, good (logistic) management and an efficient infrastructure, which includes appropriate post-harvest processes, strict food hygienic standards and a smooth flow of products throughout the supply chain, have become a necessity to survive in the export market.'

\section{LITERATURE REVIEW}

Literature has been used to provide a structure to the description and analysis of the supply chain. If the goal is to find an optimal design for the mango supply chain, its performance should be assessed and alternative supply chain should be compared with each other in order to choose 


\section{International Journal of Business Management and Economic Review}

Vol. 2, No. 05; 2019

ISSN: 2581-4664

the best option. In this research the method as suggested by Van Roekel et al. (2002) will be followed. According to them performance measurement could be done by first describing the chain systems, followed by the identification of the players in the chain with their functions, roles and relationships. The performance should subsequently be measured according to criteria as set by the chain partners. These criteria may be conflicting; therefore it needs to be determined to which criteria priority is given. Before continuing, it has to be realized that the majority of supply chains are not designed but rather developed over time (Stock and Lambert, 2001).

To be successful, mango exporters should strive to satisfy its stakeholders. Although all stakeholders are important, priority will be given to the criteria as set by the importers. If there is no demand or if the regulations of the European Union for food safety are not being met, it does not make sense to try to export to Europe. However, to make the business sustainable, the interest of other stakeholders must not be forgotten (Schary, 2001) If the mangoes are sold under a Fair Trade label and development of producer organizations needs extra attention. In those cases the satisfaction of their interests is emphasized. To structure the performance measurement in order to effectively detect possibilities for improvement, the performance objectives as defined by Slack and Lewis $(2001,2002)$ will be used.

Within the supply chain analysis a SWOT analysis will be conducted to get an overview of the alternative supply chains and to compare them with each other, as suggested by Achuonjei et al. (2003). In a SWOT analysis general Strengths, Weaknesses, Opportunities and Threats of the supply chain will be identified. In this case, the SWOT analysis will mainly act as a tool to give a structured overview of the alternatives. The analysis in this research will mainly focus on the logistics in the last part of the supply chain: the transport to the (air)port and the intercontinental transport.

The term 'supply chain' has already been used frequently in this report. Since the objective of the research is to improve the supply chain, it makes sense to make clear what the terms supply chain and logistics exactly entail. Since logistics plays an important role in the chain, this concept will also be elaborated on.

The importance of logistics is shown by different authors. According to Coughlan (1996) the physical distribution function offers a great potential for profit improvement. In many industries, distribution costs can be as much as 30 to $40 \%$ of the total costs. Besides costs, logistics also affects factors as product quality and customer satisfaction. Christopher (1998) states that if companies lack productivity advantage and value advantage, enhanced logistic management could help them to reduce costs and to increase service.

The supply chain can be seen as a set of firms that pass materials forward (La Londe and Masters, 1994) or as a network of organizations that are involved through upstream and downstream linkages, in the different processes and activities that produce value in the form of products and services delivered to the ultimate customer (Christopher, 1992).

Supply chains can thus be seen as the various firms that contribute to the product or service when it goes from its origin to its final consumer. In the mango supply chain it starts at the mango tree and ends at the consumer of the mangoes. Logistics plays a role in adding value as is 


\section{International Journal of Business Management and Economic Review}

Vol. 2, No. 05; 2019

ISSN: 2581-4664

demonstrated by Tracey (2004): 'The ultimate objective of logistics management is to enhance the total value offered to customers, be they other companies in the chain or the ultimate customers.'

Slack and Lewis (2002) define performance objectives as the dimensions of an operation's performance, with which it will be attempted to satisfy market requirements. Different stages of the supply chain will be analyzed based on the criteria as set by the chain members. In particular the requirements of importers regarding the performance objectives will be taken into account. Later in the research will be determined to what extend each criteria is important for the overall performance of the chain, i.e. the value perceived by the importer. Slack and Lewis have distinguished five performance objectives: quality, speed, reliability, flexibility and costs. Below, these objectives will be described and their relevance with respect to the research will be demonstrated.

\section{Quality}

Many definitions of quality refer to the 'specification' of a product or service, usually meaning high specification. The quality of the product is influenced by the logistical part of the supply chain. Since mangoes are perishable goods, it is obvious that time between harvest and consumption plays an important role in the process. This aspect will be discussed later in this paragraph.

The quality of the end product in the mango supply chain starts at the production. Good quality mangoes need to be produced and harvested. It will be investigated how the quality can be further influenced by logistics. Shelf life reducing bruises, cuts and scuffs can easily occur when the harvesting, transportation and handling operations are not carried out with sufficient care and attention. Maintaining the right temperature during the whole transportation and storage is of major concern. According to Thompson (2003) most defects to apples in Italy were caused during harvesting and transport to the packinghouse, rather than by maltreatment during grading and packaging, so attention should be paid to those matters. Packaging protects the mangoes against damage but can also make a difference in shelf life. But not only the right packaging plays a role. It is important to package the right mangoes, meaning that the selection should be done well. .

According to Achuonjei (2003) a subdivision of the term concept quality could be made. $\mathrm{He}$ distinguishes two types of quality:

1. quality conformance

2. quality consistency

In this case, quality conformance means compliance with European accepted standards and specifications such as EurepGAP. Also information with respect to traceability can be regarded as quality conformance. Quality consistency, on the other hand, deals with the accepted levels of variability in terms of for instance size, colour, Brix level (i.e. the percentage of sugar in a fruit) and ripeness. Thus, quality conformance deals with the processes in the supply chain (i.e. the circumstances under which the mangoes are produced handled and transported). The quality consistency refers to the physical characteristics of the mangoes. 


\section{International Journal of Business Management and Economic Review}

Vol. 2, No. 05; 2019

ISSN: 2581-4664

\section{Speed}

Speed is defined by Slack and Lewis (2002) as the time between the beginning and the end of a process. And by Slack et al (2001) as the time customers have to wait until they receive their products or services. Growing mangoes is a time-consuming process, but will not be included in the research since the velocity of this process cannot be influenced. The starting point of the time analysis in this research is the moment the mangoes are ready to be harvested. Speed in the mango supply chain refers to the time the operations take, starting at the harvest until the final customer.

Speed and quality are highly interrelated. If the (logistical) process takes too much time, the mangoes will be rotten before they have reached the final customer. What needs to be determined is the actual speed of the delivery, the desirable and acceptable speed, and which operations (unnecessarily) time consuming. A distinction has to be made in necessary (processing/transporting) time and waiting time. The latter adds costs, without adding value, so should be prevented if possible.

\section{Reliability}

The third performance criterion mentioned by Slack and Lewis (2002) is reliability. The reliability of a process says something about whether the promises with respect to the delivery are kept. A high reliability means that the delivery times given to the customers are honoured. Slack and Lewis show a linkage between speed and reliability. The lower the promised speed, the easier it is to obtain a high reliability. Dornier et al. (1998) considers speed and reliability as one performance criteria: service.

In this report the term reliability will be used, but speed and reliability will be examined separately. The reason for this lies in the fact that mangoes are perishable and therefore quoting long delivery times is not a suitable option to increase the reliability in the mango supply chain. Also the growing period of the mangoes can hardly be influenced and keeping slack in the in the process after harvesting is not desirable either, since each loss of time means less time for the importers, retailers and supermarkets to sell the product. Eventually it means a decrease of the product quality.

Reliability in the mango supply chain not only says something about the delivery dates, it also deals with the fact whether there are at least mangoes delivered and if they have the right volume and varieties. The reason why reliability is relevant to investigate lies in the fact that mangoes cannot be stored for a long time, so clients probably won't have large inventories. A low inventory results in a risk of getting out of stock if the reliability is low. In the research a distinction will be made between reliability in the short term and reliability in the long term.

\section{Reliability in the short term}

Reliability in the short term is related to the probability that the right variety and quantity of mangoes is delivered at the right time. Each part in the supply chain has to function properly, so the mangoes will be delivered on the moment that was agreed upon before. This means that both 


\section{International Journal of Business Management and Economic Review}

Vol. 2, No. 05; 2019

ISSN: 2581-4664

the capacity and speed of handling and transportation has to be sufficient.

Another important matter with respect to the reliability is the forecast of the production. Volumes, dates and sizes are usually determined and negotiated upon before the start of the mango campaign. There will be looked after possibilities to make the production forecast more reliable. Hereby, relationships and communication between the links in the supply chain play essential roles.

\section{Reliability in the long term}

The second component of reliability is the reliability of the logistical part of the supply chain in the long term. Different alternatives to transport mangoes from Vietnam to Europe are compared with eachother in this research. Since Vietnam is land-locked, the mangoes have to cross other countries if they are not transported by airfreight. To find the most suitable country in terms of reliability of the supply chain on the long term, it is necessary to assess the risks in the chain. Questions about the political (in)stability of a country, its infrastructure development and about its economic situation and their effects on the export of mangoes need to be answered.

Country risk analysis as described by Sundaram et al. (1995) is helpful to identify the economic strengths and weaknesses of a country. In his framework a country is analysed with respect to its economical performance, strategy and context. A country risk analysis could provide useful information with respect to the assessment of the mango supply chains, but it is rather time consuming as well. For this reason a full country risk analysis will not be executed in this study. Nevertheless the neighbouring countries of Vietnam that could be interesting for the mango export will be compared with each other based on economical aspects that directly influence the export and there will be briefly looked at their political situation. Since the present security situation does not allow conducting interviews in Ivory Coast, the political instability and the political risk (i.e. the probability that a political event occurs, multiplied by its impact) will be analyzed based on secondary data. Long term reliability is also influenced by the financial situation of the chain members. A bankruptcy of a chain member might influence the reliability of the chain as a whole.

\section{Flexibility}

Flexibility means being able to change the operation in some way. Slack and Lewis (2001) and Dornier (1998) distinguish several dimensions of flexibility of a logistical system:

1. Volume flexibility

2. Delivery flexibility

3. Product or service flexibility

4. Mix flexibility

It will be determined whether these different types of flexibility need improvement and which links in the supply chain are the bottlenecks for these different flexibilities.

In the mango supply chain volume flexibility relates to the effort, time and money that are required to change the capacity of the system. It means being able to anticipate to an unexpected order, but regards also to the costs and effort of stopping the operation when the there is no need anymore for logistical capacity. Mangoes are highly seasonal, so this factor has to be taken into consideration. 


\section{International Journal of Business Management and Economic Review}

Vol. 2, No. 05; 2019

ISSN: 2581-4664

Delivery flexibility is the ability to change the dates of delivery when demanded for. Since mangoes are perishable, postponing the delivery will cause a quality decrease. Nevertheless it might be possible to decrease the transportation times, for example by using airfreight instead of sea freight.

The third dimension, product flexibility is the ability of the system to deal with new products. Here could be thought of using the same system for other products than mangoes. Is it possible to combine mangoes and other products and/or can be switched to other products when mangoes are not available anymore? Mix flexibility can be seen as the ability to change sizes and varieties of the mangoes.

\section{Costs}

The price a customer is prepared to pay for products is dependent on how well the different stages of the supply chain have been executed. In order to make export feasible and sustainable for all the chain members, this price has to be higher than the total costs. Therefore it needs to be determined how cost could be reduced. Costs that are made without adding any value (e.g. unnecessary transportation, handling and administrative delays) have to be avoided. Cost savings are obviously desirable if they result in an increased efficiency. In cases however, where cost savings are at the expense of other performance characteristics such as quality and/or reliability the desirability should be judged.

\section{Using the performance criteria}

To use the performance criteria more effectively, they should be divided into two groups. The first type consists of 'hard' criteria that form a sine qua non for mango export from Vietnam to Europe. An obvious example for such a criterion is that the system must assure that the mangoes reach the consumer before they are rotten. Dornier et al. (1998) calls this type of criteria 'qualifying'. 'A qualifying criterion is defined as the minimum level, required to participate in the competition (e.g., quality for a commodity-type product.).'

On the other hand there are 'order winning' criteria. These come into play only after all the necessary criteria have been met. They differentiate and rank the alternatives. Based on these criteria the final decision is made. Dornier describes winning criteria as follows: 'A winning criteria is one that distinguishes a company relative to its competition - customers buy a firm's products because of that specific criteria (e.g., cost for a commodity-type product). Also delivery in time can be one of those criteria if the importers accept delays as long as the mangoes are still of sufficient quality

The concept of winning and qualifying criteria will be used to determine the conditions for a successful export. They show which characteristics a supply chain certainly must have and what can be done to improve the supply chain. The concept of winning and qualifying criteria will be used here to compare the performance of alternative supply chains with each other.

The research is based on the conceptual model in the figure 1 below. First, the supply chain of export mangoes will be described, hence the activities in the value chain of the exporter. Each stage of the value chain will be assessed, based on the performance criteria relating to the requirements of importers. Problems and opportunities for improvement are the result of this 


\section{International Journal of Business Management and Economic Review}

Vol. 2, No. 05; 2019

ISSN: 2581-4664

assessment. Opportunities for improvement could also be found by comparing Vietnam with neighboring countries. The relationships between producers, exporter and importer are analyzed as well. Finally, with the help of a SWOT analysis will be determined which country is most suitable to use as transit country.

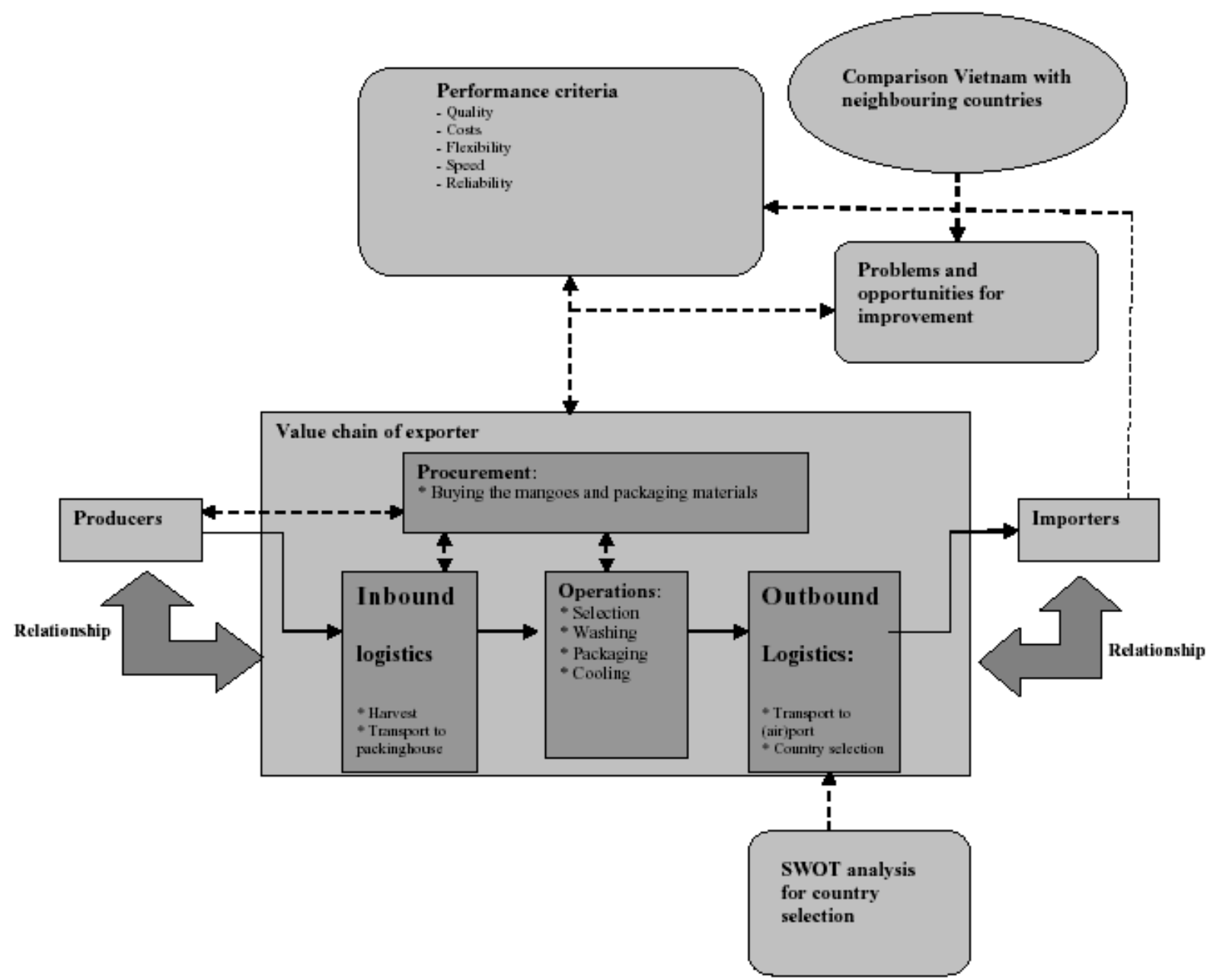

Figure 1: The conceptual model 
International Journal of Business Management and Economic Review

Vol. 2, No. 05; 2019

ISSN: 2581-4664

\section{REFERENCES}

-Achuonjei, P (2203), Analysis of the Ghanaian Fresh fruit and vegetables industry, Mission report of the Partnership for Food Industry Development Fruit and Vegetables Project, Michigan University, USA

-Coughlan and Anne T (1996), Marketing Channels, 5th ed

-Christopher, M. (1998), Marketing Logistics, Butterworth-Heinemann, UK

- Dornier et al. (1998), Global operations and logistics, John Wiley \& Sons Inc, USA

-Slack, N., Chambers, S. and Johnston, R. (2001), Operations management, Pearson Education Limited, UK

-Stock, J.R. and Lambert, D.M. (2001), Strategic Logistics Management, McGraw-Hill, USA

-Sundaram, Anant K. et al. (1995), The international business environment, Prentice Hall Inc., USA,

-Scharly, P.B. and Skott-Larsen, T. (2001), Managing the global supply chain, Copenhagen Business School Press, Danmark

-Tracey, M. (2004), Transportation effectiveness and manufacturing firm performance, The international journal of logistcs management, Vol.15, No.2

-Thompson, A.K. (2003), Fruit and vegetables: harvesting, handling and storage, Carlton, Australia, Blackwell publishing Ltd, 2003 